\title{
Language Change in Social Media (Instagram)
}

DOI: https://doi.org/10.47175/rissj.v1i2.70

\section{| Muhammad Natsir ${ }^{1}$ | Bahagia Saragih ${ }^{2}$ | Puan Suri Mira. A ${ }^{3}$ | | Rafika Dewi ${ }^{4}$ | Lidiman Sahat Martua Sinaga ${ }^{5}$ |}

\author{
$1,2,3,4,5$ English and Literature \\ Department, Faculty of \\ Languages and Arts, \\ Universitas Negeri Medan, \\ Indonesia \\ ${ }^{1}$ mnatsir0@gmail.com, \\ 2gyabucks123@gmail.com, \\ 3puansuri19@gmail.com, \\ 4fildzafayyadh@gmail.com
}

\begin{abstract}
This research was aimed to analyze the language change in Indonesian language. The analysis was focused on the Indonesian adjectives change found in social media (Instagram). This research was conducted by using qualitative method. The data of this study were the most common thirty adjectives found in social media especially Instagram. as the data source because most of young generations nowadays tend to use Instagram as a mean of communication. The researcher observed and chose the most common thirty adjectives found on Instagram by using an observation list. There were some techniques of data analysis performed, namely: determining, observing, choosing, translating, analyzing, and drawing conclusion. Based on the data analysis conducted, it was found that all the adjectives are changing into special terms which are totally different form the original words. Furthermore, language change is caused by the globalization and the interaction of people. It was also found that some of the words are changing into English. Abbreviation and contractions also occur in the process of language change. KEYWORDS

language change; adjectives; Instagram; internal and external factors
\end{abstract}

\section{INTRODUCTION}

Language is used for communication. Language is a social fact, a kind of social contract. It exists not in an individual, but in a community (Bauer, 2007). A language is a system of conventional vocal signs by means of which human beings communicate. This definition has several important terms, each of which is examined in some detail in the following sections. Those terms are system, signs, vocal, conventional, human, and communicate (Algeo, 2010). According to Saussure (1959) language is not to be confused with human speech (language), of which it is only a definite part, though certainly an essential one. It is both a social product of the faculty of speech and a collection of necessary conventions that have been adopted by a social body to permit individuals to exercise that faculty.

Language is part of linguistic field. Linguistics deals with human language. Human language is just one way in which people communicate with each other, or gather information around them. Many linguists have made contributions to this wider field. Campbell (2002) says that early developments in linguistics were considered part of philosophy, rhetoric, logic, psychology, biology, pedagogy, poetics, and religion, making it difficult to separate the history of linguistics from intellectual history in general, and, as a consequence, work in the history of linguistics has contributed also to the general history of ideas. That's why language can change and develop.

Language change is a phenomenon in which language features such as phonetic, lexis, syntax, and semantic vary as a result of the changing needs. Language can change by itself 
slowly. Language can change because of adaptation of development and pattern change and system of society life, such as level of education, social, culture and technology mastery. Language change occur internally and externally. Language change as a concept and as a subject of linguistic investigation is often regarded as something separate from the study of language in general. Language change can not be avoided. The process of language change is influenced by many factors. Some are caused by acculturation of culture, others caused by moving to another places, and also by system of society life, such as level of education, social, culture and technology mastery.

Language and society have close relation. Language is as social product with many functions in order to be used maximal by human being in communication and interaction with each others. In society, one is not only as individual who separate with other but member of society. Language is not only personality using but using in social activities. Everyone has different in using of language, phonetic, phonemic, and choosing of word, idiolect and structure of sentences. In fact, there is a lot of dialects in society. The difference of dialect of language is caused by speaker's different class, region, social status, and speaker habitual.

Language is used for communication. Human needs a means of communication to fulfill social needs. To support communication, nowadays variations of media are developed including electronic media to the printed one. Printed media provide information which can be read by the users, for example: newspaper, letter, magazine, etc. On the other hand, electronic media provide information which can be seen and listened by the users. They are television, radio, radar, telephone, computer, etc. The development of media influences communication and interaction way. It means language that used to communicate has changing. Nowadays, many social groups use special terms to communicate with others, particularly social media. The special terms that they used have caused language change.

Various forms of diversity and variety of languages will be generated from conversations and interactions in society or the community itself. It reflects the contexts in which they use the language. Variations of language view from its status as social users, gender, age, ethnicity, and type of social networking in which the person is involved. Usually, these variations arise because of the styles, the context register, and politeness. Variations occur because of the language situation in a context of the informal speech. One of the variations that appear in a variety of community is called slang. The language variation is formed by a convention or an agreement between the users of the language itself, and it is based on the nature of language as an arbiter. Moreover, slang uses informal words and expressions that are not considered standard in the speaker's language. Most people speak carefully when they are in the formal situations, but in many informal situations, a more relaxed style of speech makes a better impression.

In this study, the language change occurs in social media, especially Instagram. The most common thirty Indonesian adjectives used on Instagram to see the existence of language change. The researcher are interested in doing this study based on the researcher' own experience. Many people nowadays do not use the original words to refer things but they create their own new language. This phenomenon then leads to what is said as language change.

Based on the problem of the study above, this research will analyze how are the adjectives changing into special terms. Finally, this study is expected to contribute to the study of Lexicology especially on the subject of language change. It is also expected to be a reference for the other researchers who are in interested in this filed. 


\section{REVIEW OF LITERATURE}

\section{The Nature of Language Change}

Raymond (2003) says that any treatment of linguistics must address the question of language change. The way languages change offers insights into the nature of language itself. The possible answers to why languages change tell us about the way language is used in society, about how it is acquired by individuals and may reveal to us information about its internal organization. There is no simple explanation for why languages change. This is an area in which there is much speculation and little proof. The area is an interesting and fruitful one but there are few if any direct answers.

For this reason historical linguistics has traditionally been concerned with how languages evolve and not why they do so in one particular direction and not in another. To begin this section a number of statements about language change are made. 1) All languages change. There is no such thing as a language which is not changing. The rate of change may vary considerably due to both internal and external factors. English, for example, has changed greatly since Old English. Other languages, like Finnish and Icelandic, have changed little over the centuries. 2) Language change is largely regular. One can recognise regularities in the types of change which languages undergo, even if these cannot be predicted. (Raymond, 2003).

\section{Language Change and Development: Historical Linguistic}

Language change as a concept and as a subject of linguistic investigation is often regarded as something separate from the study of language in general. Recent research into the topic, however, has strived to highlight the continual nature of change and to emphasize that the synchronic and diachronic views of change can be unified, providing a panchronic perspective in which the relevance of small changes observed in the present can be shown to hold for larger scale changes in the past.

As generative grammar has undergone many revisions, the analyses of language change stemming from the standard theory of the mid-1960's have been left aside and more subtle and discriminating approaches have been developed. In particular, deficient analyses, which derive from the model used at the time, have been abandoned. For instance, the scholarly concern of the late 1970's with rule-ordering, particularly in phonology (see Kenstowicz and Kisseberth 1979 and Koutsoudas 1976), is now seen to result not so much from the data examined but from a non-linear, unstratified view of phonology, something which was remedied with the advent of lexical phonology and the various forms of syllablebased phonology. A language is a social fact, a kind of social contract. It exists not in an individual, but in a community (Bauer, 2007). A language is a system of conventional vocal signs by means of which human beings communicate. This definition has several important terms, each of which is examined in some detail in the following sections. Those terms are system, signs, vocal, conventional, human, and communicate (Algeo, 2010).

According to Saussure (1959) language is not to be confused with human speech, of which it is only a definite part, though certainly an essential one. It is both a social product of the faculty of speech and a collection of necessary conventions that have been adopted by a social body to permit individuals to exercise that faculty. Taken as a whole, speech is many-sided and heterogeneous; straddling several areas simultaneously-physical, physiological, and psychological-it belongs both to the individual and to society; we cannot put it into any category of human facts, for we cannot discover its unity.

Language change and development national, international or ethnic language cannot be avoided. They are caused by acculturation of culture. This case can be caused by speaker moves to other places. If someone or speaker moves to new place, the speaker will 
influence of new society, so there are new dialect, find of the new word, even syntactic structure language also change. Language can change and develop by itself slowly. Language can change and development because of adaptation of development and pattern change and system of society life, such as level of education, social, culture and technology mastery. The process of language change is influenced by many factors. In this paper the writer divides into two factors. They are internal change and external change. Internal change refers to grammatical, while external change is caused by other languages. It can fast process and usually it begins from lexicon and other language elements.

\section{Social Media Definitions}

The term social media, functions as an umbrella term that includes internet based sites and services that function for or promote social interactions between individuals that use them as an important part of their interpersonal communication (Page et al, 2014). Social media in its current form began its development in the 1980s, under the forms of bulletin board system (BBS), UseNet and Internet relay chat. These services, while not referred to as social media, are considered as their modern form precursors. What is more specifically referred to as social media is the range of tools that started to appear in the 1990s. One of the first sites that came out in 1995 was eBay. In 1997, the term web log, which was coined by Jorn Barger and was later shortened to blog by Peter Merholz, came to light. However, services that would use these names first appeared in 1999 with the arrival of Live Journal and blogger.com. The next seven years saw the rise of multiple services that are commonly used in the present, such as Wikipedia and Trip advisor, in 2001. Then, in 2003, Skype and Word Press made their debut. After that, in 2004, Facebook, which is arguably the most widespread and used service in social media, was launched. In 2005, YouTube came to existence, and the following year a service named Twitter began to operate.

The arrival of two data file formats: one for audio files, named mp3 and a flash software plug-in for web browsers, which allowed videos to be played much more easily in web browsers is what made these sites and services possible. With these two data file formats, users are allowed to create and share digital animation and audio resources more easily. This is, in short, is what lead the internet from being a mostly a text based medium to the assumption of its modern and interactive format (Boyd \& Ellison, 2007; Page et al, 2014).

Since the arrival of eBay, social media gained many different forms and functions that aim to fulfil the types of services that the users seek, such as forums, blogs, wikis, content sharing and virtual worlds. However, these are merely a few examples of all the different types of services that are available to users, as many social media services often merge forms or group them together. It is this inherent versatility that social media possesses that makes it so appealing to users. It is also the reason behind the daily increase of its clients. Currently, social media is divided into three categories:

Table 1. Three Categories of Social Media

\begin{tabular}{|c|c|c|}
\hline Communications & Collaboration & Multimedia \\
\hline Blogs, Social Nets & Wikis, Social News & $\begin{array}{l}\text { Streaming, Videos, } \\
\text { Virtual Worlds }\end{array}$ \\
\hline
\end{tabular}

These categories were defined by Cann, Dimitriou and Hooley in their booklet: social media: A Guide for Researchers (Cann et al, 2011). When people use social media, they use the service that they require. For example, services that fall under the Communications 
category, which includes services such as Facebook, Instagram, LinkedIn, and Twitter that are used by people to maintain connections and relations. If, on the other hand, people would feel the need to express themselves, they would use online journals, which have come to be known as Blogs, such as LiveJournal, WordPress and Blogger. Collaboration services are diverse, as they can serve multiple purposes, for example, Wikipedia or Wikis, which is a site for any user to collect, add or edit content using a web browser. As a part of this category, there are also social news sites such as Newsvine and Reddit, that allow anyone that signs up for their services to spread news that they feel are noteworthy.

Finally, there are Multimedia services, which are often connected to entertainment services such as video sharing sites like YouTube and Vimeo. Streaming sites like Twitch, which has users broadcast live content from their computers, are also included in this category. The content originated in streaming can include anything from playing a game to what is known as a podcast, which is somewhat similar to a radio show, with the difference that it can also be used to showcase videos as well. The final category of the Multimedia branch of social media is virtual worlds. This category includes online video game playing, and it can be referred to what is known as massive multiplayer online role playing games (MMORPGs), such as, World of Warcraft, Everquest or Final Fantasy. Additionally, there are games which are competitive in their nature, such as Counter Strike: Global offensive and Overwatch, which all belong to the first person shooting genre. There are also those referred to as Massive Online Battle Arenas (MOBAs), including games such as League of Legends (LoL), and Defence of the Ancients 2 (DOTA2) (Cann et al, 2011; Iaia, 2016).

\section{Instagram}

Instagram is generally known as a novel photo-sharing social networking platform (Chante et al., 2014; Salomon, 2013). Essentially, Instagram is a mobile-based application that enables users to take photos or pictures, apply the different manipulation tools to transform the appearance of images, and share them instantly with friends on different social networking sites (Hochman \& Schwartz, 2012). Although the application was just launched in 2010, it has grown steadily and strongly. In 2013, it was estimated that Instagram had 100 million users, and approximately four billion photos were uploaded and displayed (Abbott et al., 2013). In a more recent estimation, it is reported that around 75 million people are using Instagram on a daily basis, and approximately 16 billion photos are uploaded and shared with other users (Smith, 2014).

Instagram reaches the younger generation, and appeals to diverse societies more prevailingly than other social networking services (Abbott et al., 2013; Salomon, 2013). It has been reported that youngsters today spend more time on Instagram than Facebook (Salomon, 2013). This is likely because young mobile users are extremely driven to take photos or pictures using their mobile phones, and share them with others instantly (Abbott et al., 2013). As such, the sharing of images rather than words alone has made communication with friends and broader groups of users who share similar interests more ideal, convenient and fascinating (Bakhshi et al., 2013).

\section{Adjective}

The notion of adjective has been raised in "the definitions of traditional grammars and dictionaries which represent adjectives as complementary types of modifier: an adjective modifies a noun" (Payne, Huddleston \& Pullum, 2010, p. 31). Regarding Pustet (2006), "adjectives can be defined at various of the organization of language, in particular, at the levels of morphosyntax, semantics, syntactic usage" (p. 60). For the morphosyntax perspective, languages mostly have no independent class of adjective. Each lexicon can be 
combined with any types of grammatical items when it is used in syntactic context by investigating the position from other constituents in the higher-order syntactic configurations. Adjectives, in terms of semantic sense, refer "to express property concepts" (Pustet, 2006, p. 61). From this point of view, it shows the distinguished features which are different from other parts of speech, nouns and verbs, "whose most prototypical representatives denote object concepts and event concepts, respectively" (Pustet, 2006, p. $61)$.

Lastly, adjectives in the syntactic sense are considered as functions which consist of two aspects: attributive and predictive functions. According to Quirk et al. (1985), "adjectives are attributive when they pre-modify the head of a noun phrase; likewise, they are predicative when they function as subject complement or object complement" (p. 417). Specially, "adjectives are subject complement not only to noun phrases, but also to clauses" (Quirk et al., 1985, p. 417) which probably include finite or non-finite clauses. Adjectives can be an object complement to clauses which mostly functions to express "the result of the process denoted by the verb by using the verb be" (Quirk et al., 1985, p. 417). Adjectives sometimes can also be postpositive. That is to say, three positions of adjectives are considered.

\section{RESEARCH METHODS}

The objective of this study is to analyze the language change in the most common thirty adjectives found in social media especially Instagram. Therefore, this research was conducted qualitatively. Qualitative research is an umbrella term to refer to several research strategies that share certain characteristics. The data collected have been term soft, which is rich in description of people, places, and conversations, and not easily handled by statistical procedures, Bogdan (1992).

The data of this study were the most common thirty adjectives found in social media especially Instagram, as the data source. Instagram as the data source because most of young generations nowadays tend to use Instagram as a mean of communication. Moreover, they tend to create their own words to communicate. They do not use the original words to refer things but, people in their community still understand what they mean. This phenomenon then leads to what is known as language change.

\section{RESULT AND DISCUSSION}

There are thirty adjectives on Instagram are observed and chose. The thirty words then were translated into English.

The thirty adjectives used as the data of this study can be seen in the following table:

Table 2. The Thirty Adjectives

\begin{tabular}{cccc}
\hline No. & Adjectives (Indonesian) & Adjectives (English) & Language Change \\
\hline 1. & Palsu & Faked & Hoax \\
\hline 2. & Tua & Old & Bangkotan \\
\hline 3. & Keren & Cool & Dope \\
\hline 4. & Sadis & Sadistic & Afgan \\
\hline 5. & Jujur & Honest & TBH \\
\hline 6. & Berlebihan & Exaggerated & Lebay \\
\hline
\end{tabular}




\begin{tabular}{|c|c|c|c|}
\hline 7. & Norak & Tacky & Alay \\
\hline 8. & Enak & Delicious & Ajib \\
\hline 9. & Luar Biasa & Extraordinary & Badai \\
\hline 10. & Keras Kepala & Stubborn & Baget \\
\hline 11. & Sensitif/Bawa Perasaan & Sensitive & Baper \\
\hline 12. & Jelek & Ugly & Bapuk \\
\hline 13. & Aneh & Weird & Absurd \\
\hline 14. & Acuh & Indifferent & Damat \\
\hline 15. & Jelas/Benar & Clear / True & Danta \\
\hline 16. & Tidak Jelas & Not clear & Gaje \\
\hline 17. & Sangat Umum & Very common & Mainstream \\
\hline 18. & Menggemaskan & Adorable & Unyu \\
\hline 19. & Santai & Relaxed & Selow/Woles \\
\hline 20. & Keras & Hard & Kerad \\
\hline 21. & Bodoh & Stupid & Bedon/Dodol \\
\hline 22. & Tidak Sopan & Impolite & Keos/Songodh \\
\hline 23. & Sok Tahu & Knowledgeably & Sotoy \\
\hline 24. & Praktis & Practical & Gaway \\
\hline 25. & Adil & Fair & Cengli \\
\hline 26. & Tidak Lucu & Not funny & Garing \\
\hline 27. & Sombong & Arrogant & Jutek \\
\hline 28. & Centil & Coquettish & Menel \\
\hline 29. & Jahat & Evil & Barbar \\
\hline 30. & Membosankan & Boring & Bete \\
\hline
\end{tabular}

There were thirty adjectives used as the data of this study. Based on the table above, it can be seen that all the adjectives are changing into special terms which are totally different from the original words.

\section{How are the Adjectives Changing into Special Terms}

Language change is a phenomenon in which language features such as phonetic, lexis, syntax, and semantic vary as a result of the changing needs. Based on the table above, it can be seen that language change especially "lexis" change occurs. There are thirty words which are changing into thirty special terms. Moreover, some of the words are changing into another language that is English (palsu $\rightarrow$ hoax, jujur $\rightarrow \mathrm{TBH}$ (to be honest), aneh $\rightarrow$ absurd, sangat umum $\rightarrow$ mainstream, and santai $\rightarrow$ slow). Abbreviation and 
contractions also occurs in the process of change, for examples: TBH (to be honest), baper (bawa perasaan), and gaje (gak jelas). This phenomenon also shows the culture of modern people nowadays, in which they have a tendency to make abbreviation or contraction. It is because people nowadays have a mindset to move fast which finally affects the use of language too.

\section{CONCLUSION}

The three research questions have been answered in this study. It is found that all the adjectives are changing into special terms which are totally different from the original words.

Language change can not be avoided. The process of language change is influenced by many factors. One of the factors is globalization, in which it influences many aspects including language. Furthermore, language change is actually caused by the interaction of people. A new term cannot exist if humans together do not take a part in transferring it to other people.

Based on the data analysis conducted, it is found that language change especially "lexis" change occurs. Some of the words are changing into English. Abbreviation and contractions also occurs in the process of change. This phenomenon also shows the culture of modern people nowadays, in which they have mindset to move fast which finally affects the use of language too..

\section{REFERENCES}

Algeo, John. (2010). "The Origins and Development of English Language" USA: Wadsword.

Bauer, Lauire.(2007). The Linguistic students ‘ handbook. Edinburgh: Ediburgh University Press.

Bogdan. (1992). Qualitative Research for Education. California: Pearson A \& B.

Cann, A. J., Dimitriou, K \& Hooley. T (2011). Social media: A Guide for Researchers. Research Information Network, Web.

Campbell, Lyle. (2002)."The History of Linguistics." Blackwell Publishing Online

Hickey, Raymond. (2003). (ed.) Motives for language change. Cambridge: University Press.

Kenstowicz, Michael and Charles Kisseberth. (1979). Generative phonology. Description and theory. New York: Academic Press.

Nevalainen, T. (2016). Language Change Database: A new online research. ICAME Journal, Volume 40, 2016, DOI: 10.1515/icame-2016-0006.

Page, R, et al. (2014) Researching Language and social media: A Student Guide. Routledge. Digital

Payne, J., Huddleston, R., \& Pullum, G. K. (2010). The distribution and category status of adjectives and adverbs. Word Structure, 3(1), 31-81.

Pustet, R. (2006). Adjectives. Encyclopedia Elsevier.

Quirk, R., Greenbaum, S., Leech, G., \& Svartvik, J. (1985). A Comprehensive Grammar of the English Language. New York: Longman.

Rejeki, T.I., Sagala, R.W., (2019). Semantic Analysis of Slang in Social Media of Millenial Generation. Jurnal Kredo, Vol.3 No.1.ISSN 2598-3202.

Saussure, Ferdinand De (1959). Course in general Linguistics. New York: Philosophical Library 